\title{
High expression of TMEM180, a novel tumour marker, is associated with poor survival in stage III colorectal cancer
}

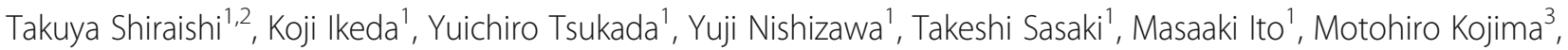
Genichiro Ishii ${ }^{3}$, Ryo Tsumura ${ }^{4}$, Sinji Saijou ${ }^{4,5}$, Yoshikatsu Koga ${ }^{4}$, Masahiro Yasunaga ${ }^{4}$ and Yasuhiro Matsumura, ${ }^{4,66^{*}}$

\begin{abstract}
Background: Transmembrane protein 180 (TMEM180) is a newly identified colorectal cancer (CRC)-specific molecule that is expressed very rarely in normal tissue and up-regulated under hypoxic conditions. We developed a monoclonal antibody (mAb) against TMEM180 and decided to examine the medical significance using the mAb.

Methods: A total of 157 patients (86 men and 71 women; median age 63.0 years) with stage III CRC who underwent curative surgery were analyzed for TMEM180 expression as a retrospective cohort design.

Immunohistochemistry with anti-TMEM180 mAb was conducted on frozen sections, and the data were evaluated for any correlation with clinicopathological indices or prognosis. SW480 CRC cells were examined to investigate the relationship between the expression of TMEM180 and tumourigenesis of xenografts.

Results: In total, 92 cases had low TMEM expression and 65 had high TMEM180 expression. For disease-free survival, hazard ratio in high-TMEM180 cases was 1.449 (95\% confidential interval $=0.802-2.619)$ higher than in lowTMEM180 cases, but the difference was not significant $(p=0.219)$. For cancer specific survival, hazard ratio in highTMEM180 cases was 3.302 (95\% confidential interval $=1.088-10.020$ ), significantly higher than in low-TMEM180 cases $(p=0.035)$. In an assay examining in vitro colony-forming activity in soft agar, SW480-WT cells clearly formed colonies, but neither KD1 nor KD2 cells did. The in vivo tumour-initiating activity of SW480 cell lines was positively correlated with the level of TMEM180 expression.

Conclusion: These results indicate that TMEM180 is a useful marker for clinical prognosis in patients with CRC. We believe that these fundamental data warrant further basic and translational studies of TMEM180, and its mAb, for development of therapeutics against CRC.
\end{abstract}

Keywords: Colorectal cancer, Prognosis, Transmembrane protein, TMEM180, Tumour marker

\footnotetext{
*Correspondence: yhmatsum@ncc.go.jp

${ }^{4}$ Division of Developmental Therapeutics, Exploratory Oncology Research \&

Clinical Trial Center, National Cancer Center, 6-5-1 Kashiwanoha, Kashiwa,

Chiba 277-8577, Japan

${ }^{5}$ Laboratory of RIN Institute Inc. 4th floor of National Cancer Center, Research

Institute, 5-1-1 Tsukiji, Tokyo 104-0045, Japan

Full list of author information is available at the end of the article
}

\section{$\triangle B M C$}

(c) The Author(s). 2021 Open Access This article is licensed under a Creative Commons Attribution 4.0 International License, which permits use, sharing, adaptation, distribution and reproduction in any medium or format, as long as you give appropriate credit to the original author(s) and the source, provide a link to the Creative Commons licence, and indicate if changes were made. The images or other third party material in this article are included in the article's Creative Commons licence, unless indicated otherwise in a credit line to the material. If material is not included in the article's Creative Commons licence and your intended use is not permitted by statutory regulation or exceeds the permitted use, you will need to obtain permission directly from the copyright holder. To view a copy of this licence, visit http://creativecommons.org/licenses/by/4.0/. The Creative Commons Public Domain Dedication waiver (http://creativecommons.org/publicdomain/zero/1.0/) applies to the data made available in this article, unless otherwise stated in a credit line to the data. 


\section{Background}

Colorectal cancer (CRC) remains one of the leading causes of cancer deaths in men and women around the world [1]. The standard treatment for patients with stage I-III CRC is surgical resection. Stage III CRC is defined as a tumour with lymph node metastasis, but no distant metastasis. Adjuvant chemotherapy has proven useful in stage III CRC patients [2], but the recurrence rates of stage III CRC patients who undergo such treatment following surgery remains about 30\% [3]. Therefore, to improve the prognosis of CRC, many prognostic biomarkers associated with outcomes in patients with CRC had been explored. The poor prognosis predictive biomarkers are likely to be of great value especially if associated with novel and effective treatments.

In this context, the identification of prognostic markers that is related with effective treatment is an urgent task for reduction of CRC mortality. Previously, we found that normal colonocytes exfoliated in stool [4]. Based on this fact, we subjected $100 \%$ pure normal colonocytes obtained from lavage solution after colonoscopy to comprehensive expression analysis, and compared them to similar data from colorectal cancer cell lines. Subsequently, we conducted RT-PCR and in situ hybridization. The results of these analyses identified transmembrane protein 180 (TMEM180), a CRCspecific multi-pass membrane protein of unknown function. According to databases and our experiments, it is clear that normal organs express this molecule very rarely if at all [5]. Thus, TMEM180 may have an important function in cancer. Our previous study suggested that TMEM180 plays an important role in the uptake or metabolism of glutamine and arginine to support tumour growth and proliferation [5]. Moreover, TMEM180 appeared to be up-regulated under hypoxic conditions. Very recently, we examined the topology of this membrane protein. We determined that it has 12 transmembrane domains, and that its $\mathrm{N}$ - and C-termini are exposed extracellularly. At the same time, we found that the TMEM180 molecule is also present in the Golgi (data not published). We also found that the putative cation-binding site of TMEM180 is conserved among orthologs, and that its position is similar to that of the melibiose transporter MelB [6]. These findings suggest that TMEM180 acts as a cation symporter. Given these results, TMEM 180 is useful for diagnosing and treating CRC, and we believe that it is important to clarify the clinicopathological relationship between TMEM180 expression and prognosis in CRC patients.

The aim of this study was to investigate the relationship between TMEM180 expression and prognosis in stage III CRC patients. In addition, we conducted in vitro and in vivo studies using a CRC cell line in order to clarify the relationship between TMEM180 expression and tumour growth. The results revealed that TMEM180 has clinical and prognostic significance, and therefore represents a novel therapeutic target for management of CRC.

\section{Methods \\ Patients and tumour tissues}

We consecutively collected CRC patients who underwent radical surgery from January 2009 to July 2013 at the National Cancer Center Hospital East. Because our anti-TMEM180 monoclonal antibody (mAb) can be used only in frozen sections, we included the patients who were obtained surgically resected frozen tissue specimens. The tissues were resected $5-10 \mathrm{~mm}$ in size and collected by pathologists after surgery before fixing the specimen, and the tissues were immediately frozen. We included pathological stage III according to UICC staging criteria, and we excluded the patients who could not obtain consent. Data of clinicopathological characteristics such as age, gender, invasion depth, the number of lymph node metastases, and pathological stage were extracted from medical and surgical reports. The 7th edition UICC TNM classification was used. Postoperative follow-up was performed for patients to confirm local or distant metastasis by laboratory tests and radiological examination. The patients were followed until the final outpatient visit or until June 2018, when the data were collected. Cancer specific survival (CSS) was defined as the interval between surgery and mortality from CRC or the last follow-up. Disease-free survival (DFS) was defined as the interval between surgery and the date of recurrence or the last follow-up. This study was approved by our institutional review board (National Cancer Center Hospital; no. K2012-001). All methods were carried out in accordance with relevant guidelines and regulations, also informed consent from patients.

\section{Immunohistochemistry (IHC) for clinical sample}

Sections of $6-\mu \mathrm{m}$ thickness were cut from all samples. Sections were fixed with $4 \%$ paraformaldehyde at room temperature for $20 \mathrm{~min}$, and then incubated with $0.3 \%$ hydrogen peroxidase at room temperature for $30 \mathrm{~min}$. To prevent nonspecific staining, the sections were preincubated with 5\% skim milk at room temperature for 60 min. Anti-TMEM180 antibody was labeled with HRP using the Peroxidase Labeling Kit-SH (Dojindo, Kumamoto City, Japan). The sections were incubated with HRP-conjugated anti-TMEM180 antibody at room temperature for $60 \mathrm{~min}$. 3,3'-diaminobenzidine tetrahydrochloride (liquid DAB+; Dako North America, Carpinteria, CA, USA) was used to reveal antigen-antibody reactions. Following counterstaining with hematoxylin, the sections were dehydrated and mounted. 


\section{Evaluation of TMEM180 expression}

Immunohistochemical evaluation was performed independently by five reviewers who were blinded to the clinicopathological details and clinical outcomes. All immunostained tissues were projected on the screen, and each case was discussed the following scoring by 5 reviewers at the same time. Both the percentage of positive cells and staining intensity were determined. Intensity of TMEM180 expression was scored as negative $=0$, low $=$ 1 , moderate $=2$, or strong $=3$ (Fig. 1 ), and the percentage of positive cells among neoplastic cells was scored as $0 \%=0,1-10 \%=1,11-50 \%=2$, or $51-100 \%=3$. These two scores were multiplied to yield an IHC score, and a score of 2 or higher was considered as high TMEM180 expression after the ROC analysis was performed to determine the optimal cut off.

\section{Cells and cell culture}

The human colon cancer cell line SW480 was purchased from the American Type Culture Collection (Manassas, VA, USA). TMEM180-knockdown SW480 cells were established according to our previously reported protocol $[5,7]$.

\section{Animal model, tumour-initiating activity, and anti-tumour activity}

All experimental protocols were approved by the Committee for Animal Experimentation of the National Cancer Center. These guidelines meet the ethical standards required by law and comply with the guidelines for the use of experimental animals in Japan.
For evaluation of tumour-initiating activity, the mice were inoculated subcutaneously in the left flank with SW480-WT/-KD cells.

\section{Statistical analysis}

Categorical variables were reported as numbers or percentages of patients, and analyzed by Chi-square or Fisher's exact test. Quantitative variables were reported as median and interquartile ranges and analyzed with the Mann-Whitney U test. Survival curves of DFS and CSS were plotted according to the Kaplan-Meier method, and the generalized logrank test was used to compare the survival curves. Univariate analyses of prognostic factors associated with DFS and CSS were performed using the Cox proportional hazards model. The Cox proportional hazards model was used to calculate hazard ratio (HR) and 95\% confidential interval (CI) for low and high TMEM180. HR and 95\% CI were calculated after adjustment for age, gender, tumour location, preoperative CEA level, tumour size, histological type tumour invasion, lymph node status, and adjuvant chemotherapy. For both the Kaplan-Meier method and Cox proportional hazards model, patients for whom more than 5 years of information were available were censored at 5 years postdiagnosis. All statistical analyses were performed using SPSS 22.0 (SPSS, Chicago, IL, USA), and the findings were considered statistically significant at $p<0.05$.

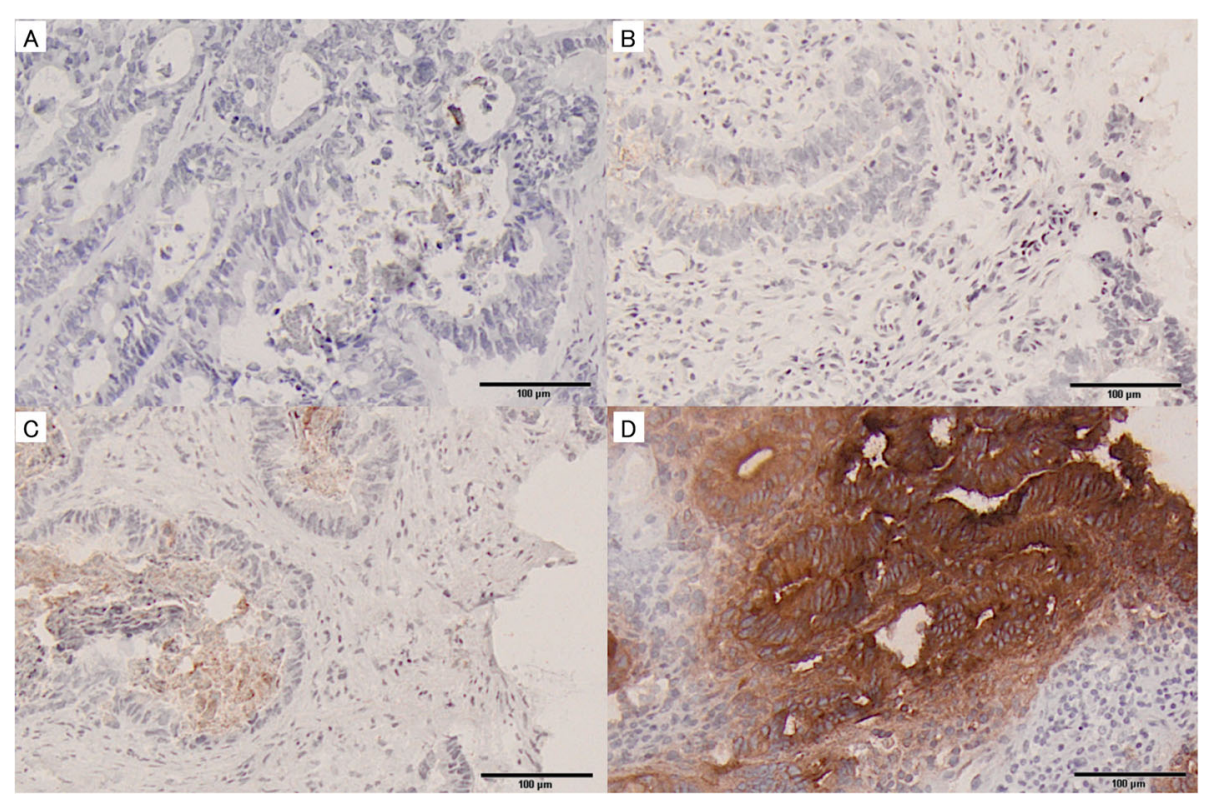

Fig. 1 Immunohistochemical analyses of TMEM180 expression in colorectal cancer. a Immunonegativity. b 1+ reactivity intensity. c 2+ reactivity intensity. $\mathbf{d} 3+$ reactivity intensity. Original magnification: $\times 100$ 


\section{Results}

The clinicopathological demographics of the patients are shown in Table 1 . The median age of the patients at the time of surgery was 63.0 years (56.0-70.0 years). The study included 86 male and 71 female patients, with a median follow-up of 66.0 months (51.5-84.0 months). In total, 83 patients $(52.9 \%)$ had colonic carcinoma, whereas 74 patients $(47.1 \%)$ had rectal carcinoma; 125 of all patients (79.6\%) received adjuvant chemotherapy.

The intensity of TMEM180 staining and percentage of TMEM180-positive cells are shown in Table 2 . TMEM180 expression was detected in 73 cases (46.5\%):

Table 1 Clinicopathological features of 157 patients with stage III colorectal cancer

\begin{tabular}{|c|c|}
\hline & All, $n=157(\%)$ \\
\hline Age, years & $63.0(56.0-70.0)$ \\
\hline \multicolumn{2}{|l|}{ Gender } \\
\hline Female & $71(45.2)$ \\
\hline Male & $86(54.8)$ \\
\hline \multicolumn{2}{|l|}{ Location } \\
\hline Colon & $83(52.9)$ \\
\hline Rectum & $74(47.1)$ \\
\hline \multicolumn{2}{|l|}{ Preoperative CEA level } \\
\hline$\leq 5 \mathrm{ng} / \mathrm{ml}$ & $89(56.7)$ \\
\hline$>5 \mathrm{ng} / \mathrm{ml}$ & $68(43.3)$ \\
\hline \multicolumn{2}{|l|}{ Histological type } \\
\hline Well- or moderately differentiated & $150(95.5)$ \\
\hline Poorly differentiated & $7(4.5)$ \\
\hline \multicolumn{2}{|l|}{ Tumour invasion } \\
\hline $\mathrm{T} 1$ & $2(1.3)$ \\
\hline $\mathrm{T} 2$ & $25(15.9)$ \\
\hline $\mathrm{T} 3$ & $108(68.8)$ \\
\hline T4 & $22(14.0)$ \\
\hline \multicolumn{2}{|l|}{ Lymph node status } \\
\hline $\mathrm{N} 1 \mathrm{a}$ & $111(70.7)$ \\
\hline $\mathrm{N} 1 \mathrm{~b}$ & $6(3.8)$ \\
\hline $\mathrm{N} 1 \mathrm{C}$ & $4(2.6)$ \\
\hline $\mathrm{N} 2 \mathrm{a}$ & $24(15.3)$ \\
\hline $\mathrm{N} 2 \mathrm{~b}$ & $12(7.6)$ \\
\hline \multicolumn{2}{|l|}{ Stage } \\
\hline$\| I I A$ & $22(14.0)$ \\
\hline$\| I \mid B$ & $120(76.4)$ \\
\hline$\| I I C$ & $15(9.6)$ \\
\hline \multicolumn{2}{|l|}{ Adjuvant chemotherapy } \\
\hline No & $32(20.4)$ \\
\hline Yes & $125(79.6)$ \\
\hline Follow-up, months & $66.0(51.5-84.0)$ \\
\hline
\end{tabular}

Table 2 Intensity of TMEM180 staining and percentage of TMEM180-positive cells

\begin{tabular}{ll}
\hline Intensity of TMEM180 staining & \\
0 & $84(53.5)$ \\
$1+$ & $30(19.1)$ \\
$2+$ & $22(14.0)$ \\
$3+$ & $21(13.4)$ \\
Percentage of TMEM180-positive cells & \\
0 & $84(53.5)$ \\
$\leq 10$ & $15(9.6)$ \\
$11-50$ & $33(21.0)$ \\
$50<$ & $25(15.9)$ \\
\hline
\end{tabular}

$1+$ in 30 cases (19.1\%), $2+$ in 22 cases (14.0\%), and $3+$ in 21 cases (13.4). The percentage of TMEM180 was also evaluated: 84 cases $(53.5 \%)$ were negative, 15 (9.6\%) were $1-10 \%$ positive, $33(21.0 \%)$ were $11-50 \%$ positive, and 25 (15.9\%) were $51-100 \%$ positive.

In total, 92 cases had low TMEM expression and 65 had high TMEM180 expression. TMEM180 expression was independent of any clinicopathological feature except gender (Table 3). The Kaplan-Meier curves for DFS and CSS of stage III CRC patients, categorized according to the level of TMEM180 expression. Patients with high TMEM180 expression exhibited poorer DFS than those with low TMEM180 expression, but the difference was not significant $(p=0.324)$ (Fig. 2a). Patients with high TMEM180 expression exhibited significantly poorer CSS than those with low TMEM180 expression ( $p=0.028$ ) (Fig. 2b). In terms of DFS, except for lymph node status $(p=0.049)$, prognosis associated with stage III CRC did not differ significantly according to age, gender, tumour location, preoperative CEA level, tumour size, histological type tumour invasion, adjuvant chemotherapy, or TMEM180 expression. On the other hand, in terms of CSS, patients whose tumours were high TMEM180 expression had a significantly worse prognosis than those whose tumours were low TMEM180 expression $(p=0.036)$ (Table 4). There was no significant difference according to age, gender, tumour location, preoperative CEA level, tumour size, histological type tumour invasion, lymph node status, or adjuvant chemotherapy. HR, calculated using the Cox proportional hazards model for TMEM180 expression after adjustment for other factors, is shown in Table 5. For DFS, HR in highTMEM180 cases was 1.449 (95\% CI $=0.802-2.619)$ higher than in low-TMEM180 cases, but the difference was not significant $(p=0.219)$. For CSS, HR in high-TMEM180 cases was $3.302 \quad(95 \% \quad \mathrm{CI}=1.088-$ 10.020), significantly higher than in low-TMEM 180 cases $(p=0.035)$. 
Table 3 Correlation between high or low TMEM180 expression and clinicopathological features

\begin{tabular}{|c|c|c|c|}
\hline & Low, $n=92$ (\%) & High, $n=65(\%)$ & $p$ \\
\hline \multicolumn{4}{|l|}{ Age, years } \\
\hline$\leq 65$ & $59(64.1)$ & $41(63.1)$ & \multirow[t]{2}{*}{0.892} \\
\hline$>65$ & $33(35.9)$ & $24(36.9)$ & \\
\hline \multicolumn{4}{|l|}{ Gender } \\
\hline Female & $35(38.0)$ & $36(55.4)$ & \multirow[t]{2}{*}{0.032} \\
\hline Male & $57(62.0)$ & $29(44.6)$ & \\
\hline \multicolumn{4}{|l|}{ Location } \\
\hline Colon & $48(52.2)$ & $35(53.8)$ & \multirow[t]{2}{*}{0.836} \\
\hline Rectum & $44(47.8)$ & $30(46.2)$ & \\
\hline \multicolumn{4}{|l|}{ Preoperative CEA level } \\
\hline$\leq 5 \mathrm{ng} / \mathrm{ml}$ & $55(59.8)$ & $34(52.3)$ & \multirow[t]{2}{*}{0.352} \\
\hline$>5 \mathrm{ng} / \mathrm{ml}$ & $37(40.2)$ & $31(47.7)$ & \\
\hline \multicolumn{4}{|l|}{ Tumour size } \\
\hline$\leq 5 \mathrm{~cm}$ & $39(42.4)$ & $23(35.4)$ & \multirow[t]{2}{*}{0.376} \\
\hline$>5 \mathrm{~cm}$ & $53(57.6)$ & $42(64.6)$ & \\
\hline \multicolumn{4}{|l|}{ Histological type } \\
\hline Well- or moderately differentiated & $89(96.7)$ & $61(93.8)$ & \multirow[t]{2}{*}{0.314} \\
\hline Poorly differentiated & $3(3.3)$ & $4(6.2)$ & \\
\hline \multicolumn{4}{|l|}{ Tumour invasion } \\
\hline$<\mathrm{T} 3$ & $15(16.3)$ & $12(18.5)$ & \multirow[t]{2}{*}{0.724} \\
\hline$T 3 \leq$ & $77(83.7)$ & $53(81.5)$ & \\
\hline \multicolumn{4}{|l|}{ Lymph node status } \\
\hline N1 & $72(78.3)$ & $49(75.4)$ & \multirow[t]{2}{*}{0.673} \\
\hline N2 & $20(21.7)$ & $16(24.6)$ & \\
\hline \multicolumn{4}{|l|}{ Adjuvant chemotherapy } \\
\hline No & $19(20.7)$ & $13(20.0)$ & \multirow[t]{2}{*}{0.920} \\
\hline Yes & $73(79.3)$ & $52(80.0)$ & \\
\hline Follow up, months & $68.0(52.3-84.8)$ & $68.0(53.5-84.5)$ & 0.531 \\
\hline
\end{tabular}

We then sought to determine whether TMEM180 is involved in tumourigenesis. In an assay examining in vitro colony-forming activity in soft agar, SW480-WT cells clearly formed colonies, but neither KD1 nor KD2 cells did (Fig. 3a). The in vivo tumour-initiating activity of SW480 cell lines was positively correlated with the level of TMEM180 expression (Fig. 3b). Therefore, loss of TMEM180 expression correlates with a loss of the tumourigenesis of SW480 CRC cells.

\section{Discussion}

This is the first study of the relationship between TMEM180 expression in CRC human tissues and patient survival. We used immunohistochemical analysis to monitor the expression of TMEM180 in human stage III CRC. We found that TMEM180 expression correlated significantly with patient survival; specifically, high TMEM180 expression was significantly correlated with poor CSS. By contrast, high expression of TMEM180 was not significantly correlated with poor DFS, although higher expression had a tendency with shorter DFS. Furthermore, high TMEM180 expression was an independent prognostic factor for poor CSS. TMEM180 expression in SW480 cells was positively correlated with anchorage-independent colony formation, and tumourigenesis.

One of the most important pathological characteristics of solid tumours is hypoxia. In a previous study, we showed that TMEM180 expression in CRC cells was upregulated by hypoxia [5]. Hypoxia is clinically associated with poor prognosis because it can adversely affect the outcome of radiotherapy and chemotherapy [8-11]. Several studies have reported that a hypoxic environment or stresses such as chemotherapy induce HIF-1 expression, followed by $\mathrm{T}$ cell anergy and increased dissemination of cancer cells [12, 13]. However, we did not closely 


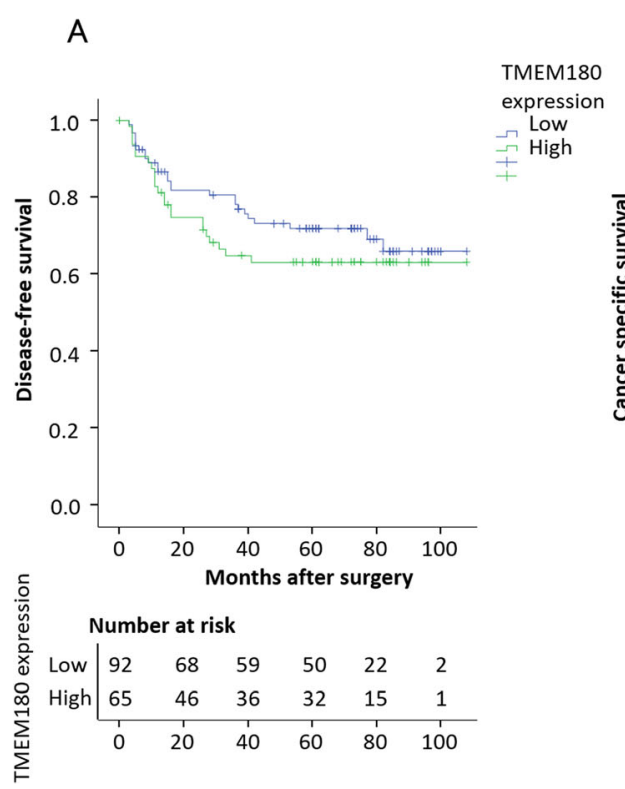

B

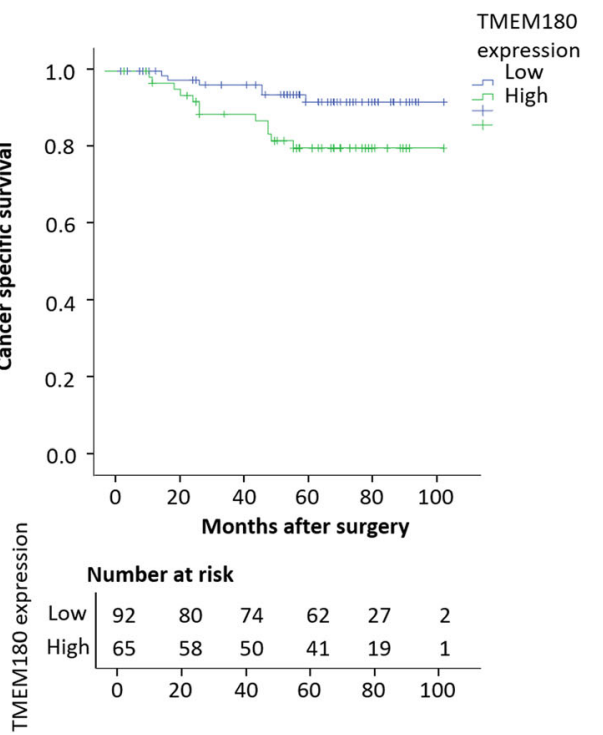

Fig. 2 Disease-free survival (DFS) and cancer specific survival (CSS) curves of CRC generated by the Kaplan-Meier method and compared by logrank test. a Patients with high TMEM180 expression exhibited poorer DFS than those with low TMEM180 expression, but the difference was not significant $(p=0.324)$. b Patients with high TMEM180 expression exhibited significantly poorer CSS than those with low TMEM180 expression $(p=0.028)$

examine its relationship to expression such as hypoxia inducible factor (HIF)-1 and carbonic anhydrase IX in the present TR study. Although we are investigating the function of TMEM180 using several methods including proteomics, next generation sequence, metabolomics and oxygen consumption, there is no doubt that the expression of this molecule is increased by hypoxia in cancer cells. Indeed, we found that TMEM180 possesses 10 hypoxia-responsive element (HRE) consensus sequences in its promoter region [5]. We consider that it should be clarified whether TMEM180 expression occurs in HIFdependent or HIF-independent systems soon. In addition, we have reported that TMEM180 have 12 transmembrane domains and found that putative cation binding site of TMEM180MelB [6]. These results suggest that TMEM180 would act as a cation symporter. Very recently, we have reported that TMEM180 may cause variation in metabolites related to glycolysis [14]. We are going to identify the substrates that are transported by coupling with cations in order to clarify the relationship between TMEM180 expression and tumour growth. Although information is limited, our data suggest that TMEM180 is involved in tumour growth.

Our data indicate that specific treatment and rigorous follow-up are needed for CRCs with high TMEM180 expression. Cetuximab is an anti-EGFR mAb that is widely used in patients with CRC. However, the use of cetuximab is limited to CRC patients with wild-type KRAS and has serious skin toxicity due to the high expression of EGFR in normal skin. On the other hand, anti-
TMEM180 mAb exerts a significant antitumour effect in CRC xenografts with mutant KRAS [5]. Since this is very important in constructing the design of future clinical trials, we are conducting experiments to compare the effects of anti-TMEM180 antibody and anti-EGFR antibody on several patients derived xenografts of CRC with or without KRAS mutation. In regard to toxicity, a previous IHC study by our group revealed no TMEM180 expression in any major organ, including skin, brain, heart, lung, liver, intestine, and kidney. Moreover, our study of TMEM180-KO mice did not reveal any embryonic, neonatal, or postnatal lethality [5]. According to these data, we anticipate that unpredictable adverse effects are unlikely to occur in a clinical trial of anti-TMEM180 mAb. Our $\mathrm{mAb}$ is now being processed according to Good Manufacturing Practice (GMP) principles for testing in a first-in-human clinical trial.

This study had some limitations. First, it was a retrospective study at a single institution and had a small sample size. Because only stage III cases were targeted, other stages cases were not analyzed. Accordingly, further analysis using a larger population is needed to clarify the prognostic significance of CRC patients with TMEM180 expression. Second, we used frozen tissue specimens stored for long periods of time, and it is possible that the tissues had deteriorated. Third, we only used SW480 cell lines in this study and reported the positively correlation with anchorageindependent colony formation and tumourigenesis. 
Table 4 Univariate analyses of the prognostic factors for disease-free survival (DFS) and cancer specific survival (CSS)

\begin{tabular}{|c|c|c|c|c|c|c|c|c|c|}
\hline Variable & $\mathrm{n}$ & 5-year DFS (\%) & HR & $95 \% \mathrm{Cl}$ & $p$ & 5-year CSS (\%) & HR & $95 \% \mathrm{Cl}$ & $p$ \\
\hline Age, years & & & & & 0.463 & & & & 0.318 \\
\hline$\leq 65$ & 100 & 72.0 & 1.000 & $0.698-2.204$ & & 91.0 & 1.000 & $0.634-4.079$ & \\
\hline$>65$ & 57 & 66.7 & 1.240 & & & 87.7 & 1.608 & & \\
\hline Gender & & & & & 0.808 & & & & 0.412 \\
\hline Female & 86 & 70.9 & 1.000 & $0.612-1.880$ & & 91.9 & 1.000 & $0.583-3.742$ & \\
\hline Male & 71 & 69.0 & 1.072 & & & 87.3 & 1.476 & & \\
\hline Tumour location & & & & & 0.052 & & & & 0.768 \\
\hline Colon & 83 & 75.9 & 1.000 & $0.994-3.110$ & & 90.4 & 1.000 & $0.456-2.896$ & \\
\hline Rectum & 74 & 63.5 & 1.759 & & & 89.2 & 1.149 & & \\
\hline Preoperative CEA level & & & & & 0.957 & & & & 0.776 \\
\hline$\leq 5 \mathrm{ng} / \mathrm{ml}$ & 89 & 69.7 & 1.000 & $0.541-1.693$ & & 89.9 & 1.000 & $0.445-2.960$ & \\
\hline$>5 \mathrm{ng} / \mathrm{ml}$ & 68 & 70.6 & 0.957 & & & 89.7 & 1.148 & & \\
\hline Tumour size & & & & & 0.632 & & & & 0.789 \\
\hline$\leq 5 \mathrm{~cm}$ & 62 & 66.1 & 1.000 & $0.496-1.531$ & & 88.7 & 1.000 & $0.340-2.67$ & \\
\hline$>5 \mathrm{~cm}$ & 95 & 72.6 & 0.872 & & & 90.5 & 0.878 & & \\
\hline Histological type & & & & & 0.605 & & & & 0.678 \\
\hline Well- or moderately differentiated & 150 & 70.7 & 1.000 & $0.423-4.378$ & & 90.0 & 1.000 & $0.204-11.534$ & \\
\hline Poorly differentiated & 7 & 57.1 & 1.361 & & & 85.7 & 1.534 & & \\
\hline Tumour invasion & & & & & 0.906 & & & & 0.871 \\
\hline$<\mathrm{T} 3$ & 27 & 70.4 & 1.000 & $0.712-1.467$ & & 92.6 & 1.000 & $0.321-3.827$ & \\
\hline$T 3 \leq$ & 130 & 70.0 & 1.022 & & & 89.2 & 1.108 & & \\
\hline Lymph node status & & & & & 0.049 & & & & 0.993 \\
\hline N1 & 107 & 73.6 & 1.000 & $1.003-3.311$ & & 88.4 & 1.000 & $0.572-1.739$ & \\
\hline N2 & 36 & 58.3 & 1.822 & & & 94.4 & 0.997 & & \\
\hline Adjuvant chemotherapy & & & & & 0.717 & & & & 0.122 \\
\hline No & 32 & 71.9 & 1.000 & $0.554-2.361$ & & 87.5 & 1.000 & $0.157-1.244$ & \\
\hline Yes & 125 & 69.6 & 1.144 & & & 90.4 & 0.442 & & \\
\hline TMEM180 expression & & & & & 0.328 & & & & 0.036 \\
\hline Low & 92 & 73.9 & 1.000 & $0.755-2.320$ & & 94.6 & 1.000 & $1.071-7.603$ & \\
\hline High & 65 & 64.6 & 1.323 & & & 83.1 & 2.853 & & \\
\hline
\end{tabular}

As previously reported, the xenografts model showed the most significant effect in therapeutic experiments with the antibody of SW480 cell lines [5]. However, other recent basic experiments have confirmed that knockout cells of other colorectal

Table 5 Multivariate analyses of prognostic factors for diseasefree survival (DFS) and cancer specific survival (CSS)

\begin{tabular}{clllllll}
\hline Variable & DFS & & & & CSS & \\
\cline { 2 - 3 } & $\mathbf{H R}^{\mathbf{a}}$ & $\mathbf{9 5 \%} \mathbf{C l}$ & $\mathbf{p}$ & & $\mathbf{H R}^{\mathbf{a}}$ & $\mathbf{9 5 \%} \mathbf{C l}$ & $\mathbf{p}$ \\
\hline TMEM180 & & & 0.219 & & & 0.035 \\
Low & 1.000 & $0.802-2.619$ & & 1.000 & $1.088-10.020$ & \\
High & 1.449 & & & 3.302 & & \\
\hline
\end{tabular}

HR hazard ratio, $\mathrm{Cl}$ confidence interval

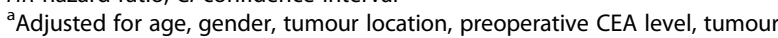
size, histological type tumour invasion, lymph node status, and adjuvant chemotherapy cancer cells, LoVo and DLD-1, have a clearly reduced proliferative capacity compared to their parent strains. However, despite these limitations, our results suggested that expression of TMEM180 is an important prognostic factor in stage III CRC patients. Undoubtedly, a prospective study is needed to confirm the conclusion. We are now developing an antibody suitable for IHC using FFPE samples; this would allow us to perform a translational study using larger numbers of archival samples. 
A

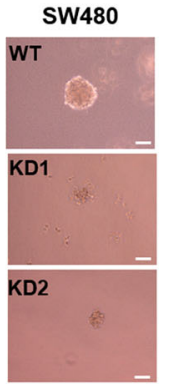

B

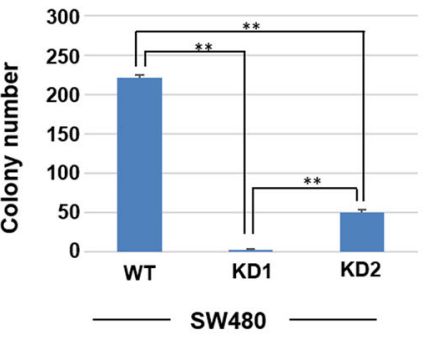

Incidence of tumour (SW480)

\begin{tabular}{cccc}
\hline \multirow{2}{*}{$\begin{array}{c}\text { No. of trans- } \\
\text { planted cells }\end{array}$} & \multicolumn{3}{c}{ TMEM180 } \\
\cline { 2 - 4 } & WT & KD1 & KD2 \\
\hline $10^{7}$ & $6 / 6$ & $0 / 6$ & $3 / 6$ \\
$10^{6}$ & $4 / 6$ & $0 / 6$ & $0 / 6$ \\
\hline
\end{tabular}

Fig. 3 Relationship between TMEM180 expression and the tumourigenesis of SW480 CRC cells. a In an assay examining in vitro colony-forming activity in soft agar, SW480-WT cells formed colonies, whereas KD1 and KD2 did not. b The in vivo tumour-initiating activity of SW480 cell lines was positively correlated with the level of TMEM180 expression

\section{Conclusion}

We found that TMEM180 expression was significantly associated with poor CSS. Furthermore, high TMEM180 expression was an independent prognostic factor for poor CSS. We showed that TMEM180 expression is involved in tumour proliferation. We believe that these fundamental data warrant further basic and translational studies of TMEM180, and its mAb, for development of therapeutics against CRC.

\section{Abbreviations}

CRC: ColoRectal Cancer; TMEM 180: TransMEMbrane protein 180; mAb: Monoclonal Antibody; CSS: Cancer Specific Survival; DFS: Disease-Free Survival; HIC: ImmunoHistoChemistry; HR: Hazard Ratio; Cl: Confidential Interval; HRE: Hypoxia-Responsive Element; HIF: Hypoxia Inducible Factor

\section{Acknowledgements}

We thank Mrs. M Ohmaru for her technical assistance and Mrs. H Shindo for her secretarial assistance.

\section{Authors' contributions}

YM provided the original concept. TS and YM analyzed data and drafted the manuscript. KI, YT, YN, TS, MI, MK, GI, RT, SS, YK, and MY were involved in interpretation of results. The author(s) read and approved the final manuscript.

\section{Funding}

This study was supported by the National Cancer Center Research and Development Fund (29-A-9 to Y.M.) from the National Cancer Center, Japan and Project for Cancer Research and Therapeutic Evolution from the Japan Agency for Medical Research and Development (AMED, 17cm0106415h0002 to Y.M.).

\section{Availability of data and materials}

The datasets used and/or analysed during the current study available from the first author TS on reasonable request.

\section{Declarations}

\section{Ethics approval and consent to participate}

All procedures performed in studies involving human participants were in accordance with the ethical standards of the institutional and/or national research committee and with the 1964 Helsinki declaration and its later amendments or comparable ethical standards. All patients who were obtained surgically resected frozen tissue specimens used by this study gave informed consent, and the consent was obtained in writing. All experimental protocols were approved by the Committee for Animal Experimentation of the National Cancer Center. This study was carried out in compliance with the ARRIVE guidelines. This study was approved by our institutional review board (National Cancer Center Hospital Approval no. K2012-001).

\section{Consent for publication}

Not applicable.

\section{Competing interests}

YM is co-founder, shareholder and Board Member of RIN Institute Inc., the company that owns the anti-TMEM180 antibody. MY is shareholder of RIN Institute Inc. SS is an employee of RIN Institute Inc. Others declare no competing interests.

\section{Author details}

${ }^{1}$ Department of Colorectal Surgery, National Cancer Center Hospital East, 6-5-1 Kashiwanoha, Kashiwa, Chiba 277-8577, Japan. 'Department of General Surgical Science, Gunma University Graduate School of Medicine, 3-39-22 Showa-machi, Maebashi, Gunma 371-8511, Japan. ${ }^{3}$ Pathology Division, National Cancer Center Hospital East, Kashiwa, 6-5-1 Kashiwanoha, Kashiwa, Chiba 277-8577, Japan. ${ }^{4}$ Division of Developmental Therapeutics, Exploratory Oncology Research \& Clinical Trial Center, National Cancer Center, 6-5-1 Kashiwanoha, Kashiwa, Chiba 277-8577, Japan. ${ }^{5}$ Laboratory of RIN Institute Inc. 4th floor of National Cancer Center, Research Institute, 5-1-1 Tsukiji, Tokyo 104-0045, Japan. ${ }^{6}$ Department of Immune Medicine, National Cancer Center Research Institute, 5-1-1 Tsukiji, Chuo-ku, Tokyo 104-0045, Japan.

Received: 1 December 2020 Accepted: 15 March 2021

Published online: 23 March 2021

\section{References}

1. Ferlay J, Shin HR, Bray F, Forman D, Mathers C, Parkin DM. Estimates of worldwide burden of cancer in 2008: GLOBOCAN 2008. Int J Cancer. 2010; 127(12):2893-917. https://doi.org/10.1002/ijc.25516.

2. Yaffee P, Osipov A, Tan C, Tuli R, Hendifar A. Review of systemic therapies for locally advanced and metastatic rectal cancer. J Gastrointest Oncol. 2015;6:185-200.

3. Tsikitis VL, Malireddy K, Green EA, Christensen B, Whelan R, Hyder J, Marcello P, Larach S, Lauter D, Sargent DJ, Nelson H. Postoperative surveillance recommendations for early stage colon cancer based on results from the clinical outcomes of surgical therapy trial. J Clin Oncol. 2009;27(22):3671-6. https://doi.org/10.1200/JCO.2008.20.7050.

4. Yamao T, Matsumura Y, Shimada Y, Moriya Y, Sugihara Kl, Akasu T, Fujita S, Kakizoe T. Abnormal expression of CD44 variants in the exfoliated cells in the feces of patients with colorectal cancer. Gastroenterology. 1998;114(6): 1196-205. https://doi.org/10.1016/S0016-5085(98)70425-1.

5. Yasunaga M, Saijou S, Hanaoka S, Anzai T, Tsumura R, Matsumura Y. Significant antitumour effect of an antibody against TMEM180, a new colorectal cancer-specific molecule. Cancer Sci. 2019;110(2):761-70. https:// doi.org/10.1111/cas.13907.

6. Anzai T, Matsumura Y. Topological analysis of TMEM180, a newly identified membrane protein that is highly expressed in colorectal cancer cells. 
Biochem Biophys Res Commun. 2019;520(3):566-72. https://doi.org/10.1016/ j.bbrc.2019.10.070.

7. Saito Y, Hashimoto Y, Kuroda JI, Yasunaga M, Koga Y, Takahashi A, Matsumura Y. The inhibition of pancreatic cancer invasion-metastasis cascade in both cellular signal and blood coagulation cascade of tissue factor by its neutralisation antibody. Eur J Cancer. 2011;47(14):2230-9. https://doi.org/10.1016/j.ejca.2011.04.028.

8. Wilson WR, Hay MP. Targeting hypoxia in cancer therapy. Nat Rev Cancer. 2011;11(6):393-410. https://doi.org/10.1038/nrc3064.

9. Brown JM. Tumour hypoxia, drug resistance, and metastases. J Natl Cancer Inst. 1990;82(5):338-9. https://doi.org/10.1093/jnci/82.5.338.

10. Minard FN, Grant DS. Hypothermia as a mechanism for drug-induced resistance to hypoxia. Biochem Pharmacol. 1982;31 (7):1197-203. https://doi. org/10.1016/0006-2952(82)90004-1.

11. Sakata K, Kwok TT, Murphy BJ, Laderoute KR, Gordon GR, Sutherland RM. Hypoxia-induced drug resistance: comparison to P-glycoprotein-associated drug resistance. Br J Cancer. 1991;64(5):809-14. https://doi.org/10.1038/bjc.1 991.405.

12. Loboda A, Jozkowicz A, Dulak J. HIF-1 and HIF-2 transcription factors--similar but not identical. Mol Cell. 2010;29(5):435-42. https://doi.org/10.1007/s1 0059-010-0067-2.

13. Lu H, Chen I, Shimoda LA, Park Y, Zhang C, Tran L, Zhang H, Semenza GL. Chemotherapy-induced $\mathrm{Ca}^{2+}$ release stimulates breast Cancer stem cell enrichment. Cell Rep. 2017;18(8):1946-57. https://doi.org/10.1016/j.celrep.201 7.02.001.

14. Anzai T, Saijou S, Ohnuki Y, Kurosawa H, Yasunaga M, Matsumura Y. TMEM180 contributes to colorectal cancer proliferation through intracellular metabolic pathways. bioRxiv. 2020. https://doi.org/10.1101/2020.07.16.2 07712.

\section{Publisher's Note}

Springer Nature remains neutral with regard to jurisdictional claims in published maps and institutional affiliations.

Ready to submit your research? Choose BMC and benefit from:

- fast, convenient online submission

- thorough peer review by experienced researchers in your field

- rapid publication on acceptance

- support for research data, including large and complex data types

- gold Open Access which fosters wider collaboration and increased citations

- maximum visibility for your research: over $100 \mathrm{M}$ website views per year

At $\mathrm{BMC}$, research is always in progress.

Learn more biomedcentral.com/submissions 